K. MASUTOMi, H. SUGiYAmA, H. UEKUSA, Y. ShiBATA, K. TANAKA* (TOKYO INSTitute OF TECHNOLOGY, JAPAN)

Asymmetric Synthesis of Protected Cyclohexenylamines and Cyclohexenols by Rhodium-Catalyzed [2+2+2]

Cycloaddition

Angew. Chem. Int. Ed. 2016, 55, 15373-15376.

\title{
Cyclohexenylamines and Cyclohexenols by Rhodium-Catalyzed Cycloaddition
}

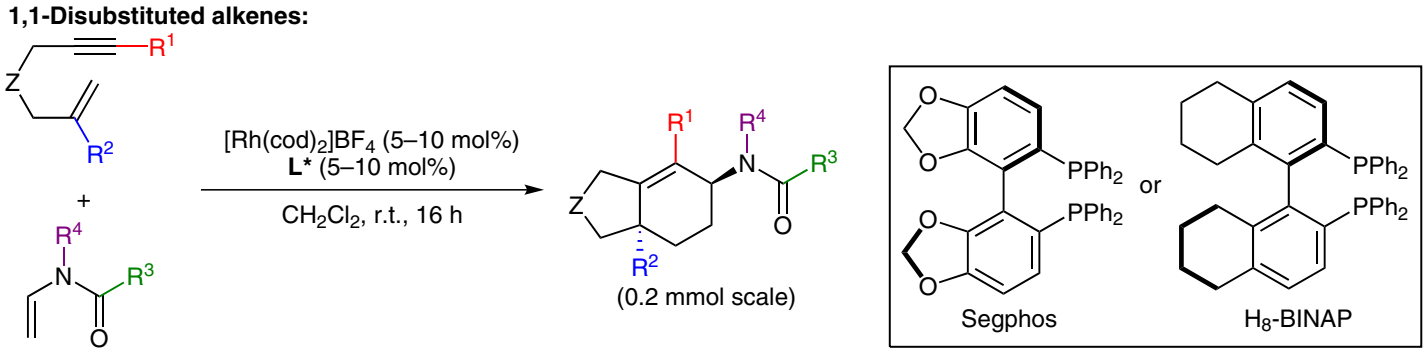

(1.1 equiv)
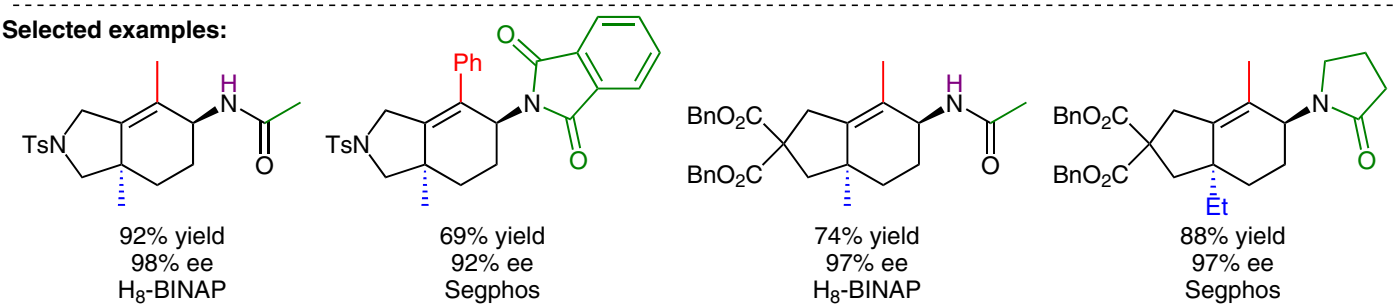

Monosubstituted alkenes:

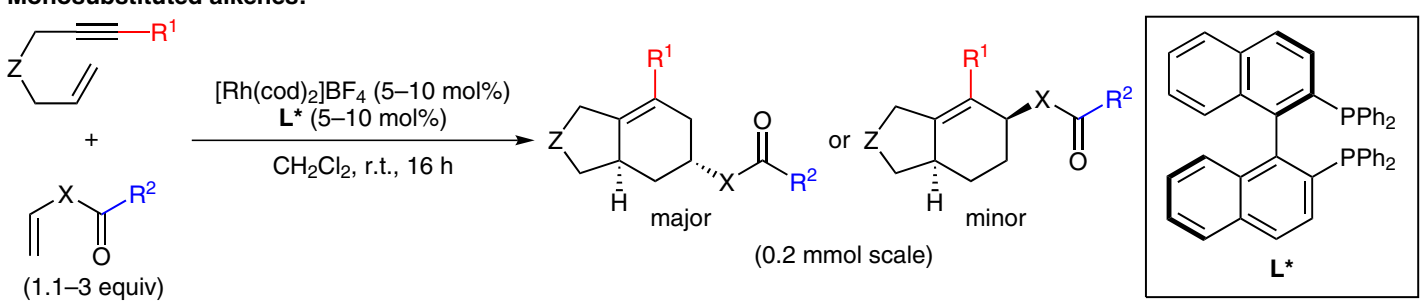

(1.1-3 equiv)

(0.2 $\mathrm{mmol}$ scale)

Selected examples:
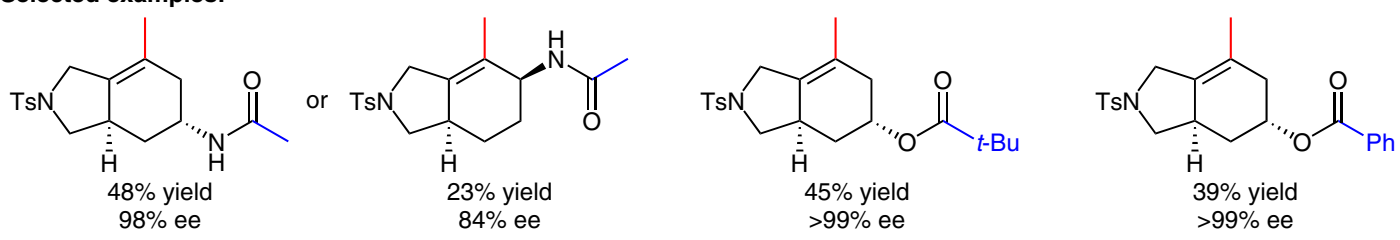

Significance: Transition-metal-catalyzed [2+2+2] cycloadditions of diynes or enynes with unsaturated moieties have become an attractive method for the stereoselective construction of carbocycles. Herein, Tanaka and co-workers report a regiodivergent asymmetric rhodium-catalyzed $[2+2+2]$ cycloaddition generating cyclohexenylamines and cyclohexenols.
Comment: The rhodium-catalyzed [2+2+2] cycloaddition of enynes bearing 1,1-disubstituted olefins provided the desired products in moderate to excellent yields and with excellent enantioselectivities. Interestingly, by employing enynes with monosubstituted olefins, a different regioisomer is reported to be formed in moderate yields and with excellent enantioselectivities.

SYNFACTS Contributors: Mark Lautens, Hyung Yoon

Dol: 10.1055/s-0036-1589746; Reg-No.: L13916SF 